\title{
Compact Fractal MIMO antenna for UWB applications.
}

\author{
EDGAR ALEJANDRO ANDRADE-GONZALEZ1 ${ }^{1}$, JUAN CARLOS ORDOÑEZ-MARTÍNEZ, \\ MARIO REYES-AYALA ${ }^{1}$, JOSÉ ALFREDO TIRADO ${ }^{2}$ MÉNDEZ, HILARIO TERRES-PEÑA $^{3}$ \\ ${ }^{1}$ Electronics Department, Instituto Politécnico Nacional, ESIME, MEXICO \\ ${ }^{2}$ Metropolitan Autonomous University Electrical Engineering Department, Instituto Politécnico \\ Nacional, ESIME, MEXICO \\ ${ }^{3}$ Energy Department, Instituto Politécnico Nacional, ESIME, MEXICO
}

\begin{abstract}
In this article, a compact ultra-wide band (UWB) multiple input multiple output (MIMO) antenna system is showed. This antenna is based on fractal Fibonacci circles and operates over wide frequency range from 2.9 to $14.51 \mathrm{GHz}$. The dielectric used was Duroid substrate with dielectric constant $\varepsilon_{\mathrm{r}}=2.2$ and thickness of substrate $1.27 \mathrm{~mm}$. This UWB MIMO antenna is simulated by HFSS. In order to improve the isolation between the elements of the antenna a parasitic structure is used, getting $\mathrm{S}_{12}$ and very low ECC. Also, the Total Active reflection Coefficient (TARC) was obtained. Proposed antenna can be used for UWB communication applications and its size is $64 \times 38 \mathrm{~mm}^{2}$.
\end{abstract}

Key-Words: - UWB MIMO antenna, Fibonacci circles, ECC, TARC, antenna bandwidth, antenna pattern, parasitic element.

Received: March 3, 2021. Revised: August 16, 2021. Accepted: August 22, 2021. Published: August 30, 2021.

\section{Introduction}

Modern communication applications based on the IP protocol, the augmented reality, the virtual reality and real time in mobile communication systems, demand high transmission data rates. Nowadays, due to the large number of devices based on the Internet of Things (IoT), require bandwidths that allow them to be controlled and communicated remotely at any moment of time. In $4 \mathrm{G}$ systems, there are several strategies to achieve these data rates such as the use of coding schemes, modulation, access schemes, massive MIMO, etc.

Additionally, UWB systems have advantages such as high transmission capacity, low power consumption, high electromagnetic compatibility, high simplicity in terminal equipment, low probability of being interfered with, among others [1][2]. This makes UWB systems ideal for today's portable communications.

Multiple input and multiple output (MIMO) antennas can increase network capacity, present spectral efficiency and energy efficiency thanks to the diversity presented, in addition to reducing susceptibility to being jammed as well as fading due to multipath.
The need to use MIMO antennas in portable devices in order to achieve higher transmission data rates, presents the difficulty that the elements of the MIMO antennas tend to be very close to each other, so the coupling of electromagnetic fields radiated by them affect the others by limiting their performance [3].

Fractal geometry helps reduce antenna size thanks to its self-similarity and space-filling properties, these properties help multiband or broadband behavior to occur in antennas [4][5][6][7][8][9][10][11].

There are several techniques that allow to improve the isolation between the radiators of a MIMO antenna, such as the use of coupling networks, meandering lines, Defected Ground Structures, among others [12]. In this paper, a fractal MIMO antenna for UWB applications is presented, with a parasitic element structure as a technique to increase the isolation, in order to improve the isolation in the proposed antenna by reducing the size of the antenna and improving its performance. The antenna is designed on a Duroid substrate with a dielectric constant of 2.2 and a thickness of $1.27 \mathrm{~mm}$, it has two elements positioned orthogonally $\left(90^{\circ}\right)$. 


\section{Antenna Design.}

The figure 1 shows the fractal structure implemented, which is based on the Fibonacci circles, as in [13], where in addition, the Krauss technique and beveling were used to improve the coupling and reducing the original size of the antenna showing a bandwidth greater than required in UWB systems. The Fibonacci sequence helped achieve a wide frequency range beyond UWB required.

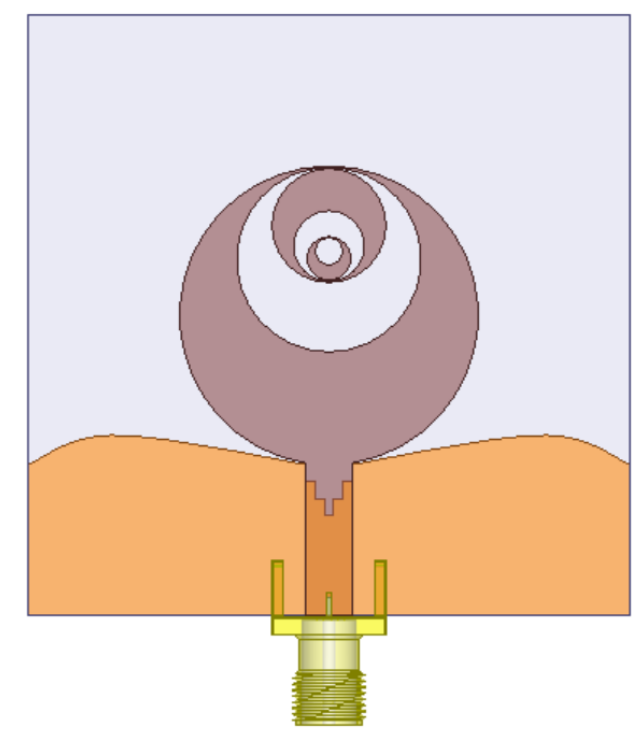

Fig. 1 Inscribed fractal Fibonacci circles.

The antenna presented in this paper, only the beveling technique was used in a semicircular ground plane in order to reduce its size, unlike [14] where the Krauss technique was also used to avoid abrupt changes in the ground plane.

The MIMO antenna is composed of two orthogonally positioned radiator elements as shown in figure 2 , the configuration reduces the correlation between the fields generated by the radiators and therefore their coupling.

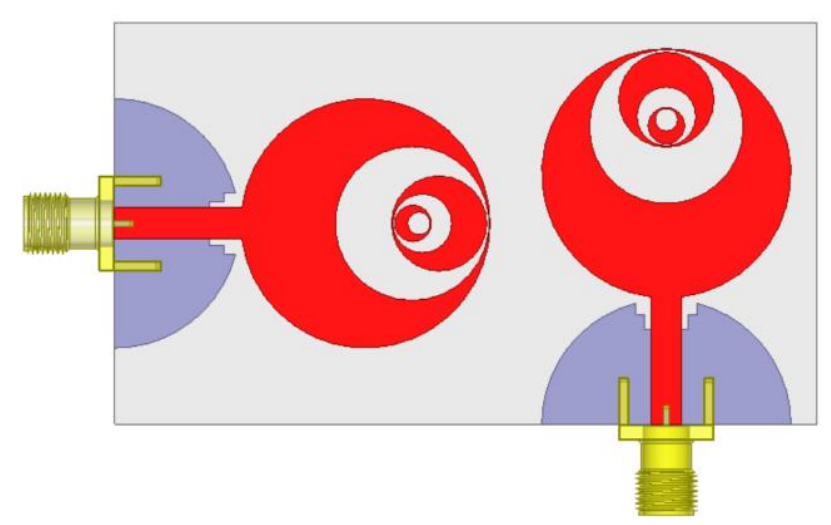

Fig. 2 MIMO antenna configuration.

\section{Results.}

With the distribution of the radiators shown in figure 2 , one more level was implemented in the beveling technique, resulting in a MIMO antenna size of $40 \times 70 \mathrm{~mm}^{2}$. The antenna features a bandwidth of $11.85 \mathrm{GHz}(2.81-14.67 \mathrm{GHz})$ with a small decoupling from 4.58 to $5.1 \mathrm{GHz}$ with a maximum peak of $-9.28 \mathrm{~dB}$ of return losses. Parameter $\mathrm{S}_{12}$ shown in the entire bandwidth shows an average value of $-25.44 \mathrm{~dB}$ and with values greater than -5.34 $\mathrm{dB}$, which is acceptable.

With the same configuration of the MIMO antenna (figure 2), the height of the bevel step was varied to $1.48 \mathrm{~mm}$ unlike to $1.45 \mathrm{~mm}$, improving its bandwidth to $12.07 \mathrm{GHz}$ as shown in figure 3 , as well as the isolation between ports at values greater than -17.01 $\mathrm{dB}$ (figure 4). However, decoupling is still showing in the same frequency range mentioned above.

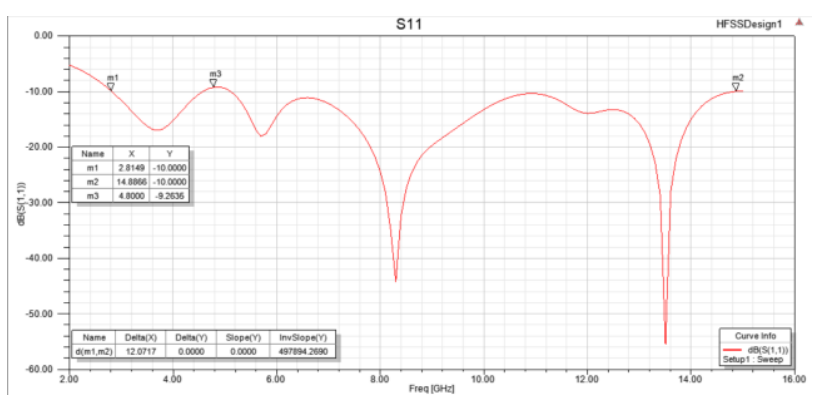

Fig. 3 Return losses $\mathrm{S}_{11}$.

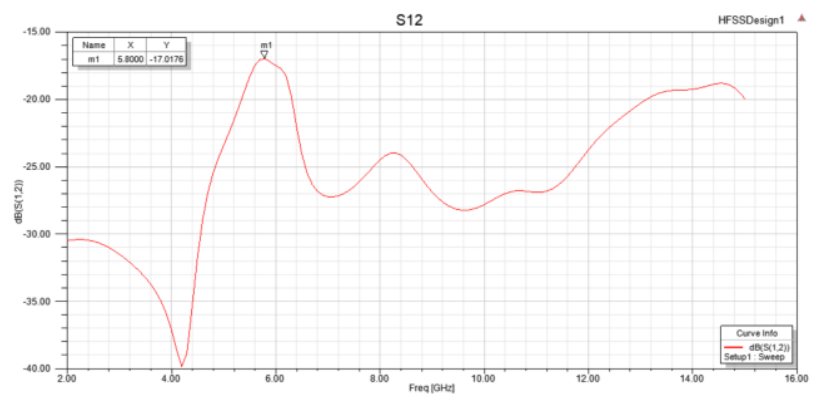

Fig. 4 Isolation $\mathrm{S}_{12}$.

The scattering parameter $S_{12}$ presented, is greater than $-15 \mathrm{~dB}$, the radiating elements were approached each other and in the same way the size of the antenna was reduced to a size of $38 \times 64 \mathrm{~mm}$. (figure 5), reducing its bandwidth to $11.69 \mathrm{GHz}$ as shown in figure 6 , however, the mismatching peak was reduced too, improving to a maximum peak of -9.68 $\mathrm{dB}$ (VSWR <2) and reducing in the same way the mismatching bandwidth. 


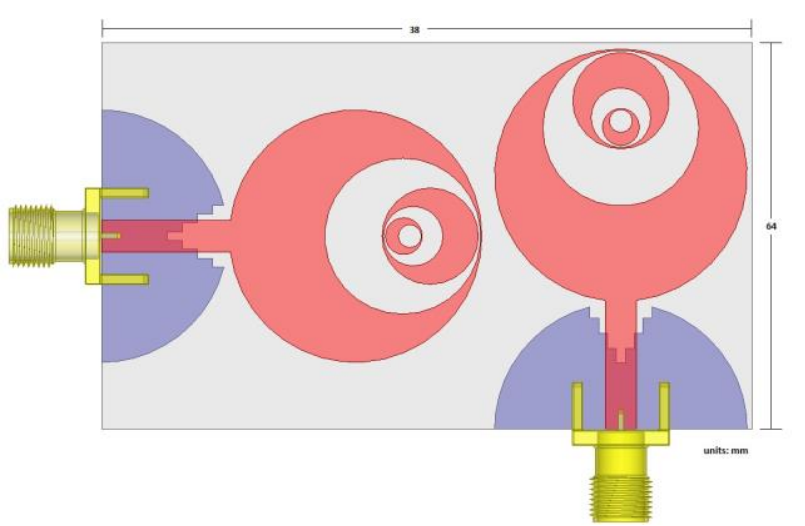

Fig. 5 MIMO antenna size.

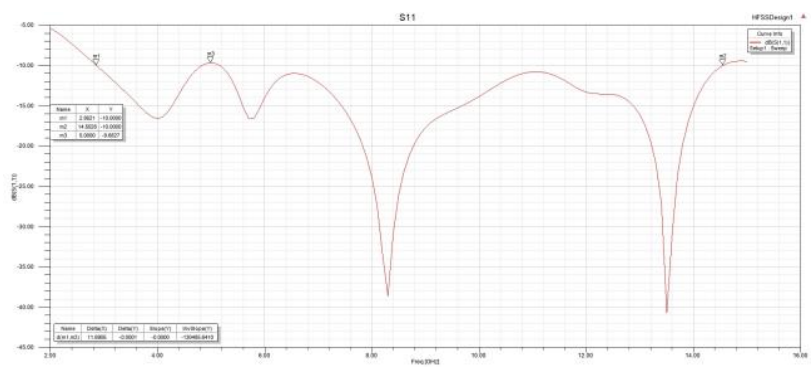

Fig. 6 Return losses $\mathrm{S}_{11}$.

In figure 7, the parameter $S_{12}$ presents values greater than $-15 \mathrm{~dB}$ in the range of $5.65-5.98 \mathrm{GHz}$, for this reason, it is essential to use a technique that improves the isolation without having to increase the size of the antenna or increase the distance between the element radiators.

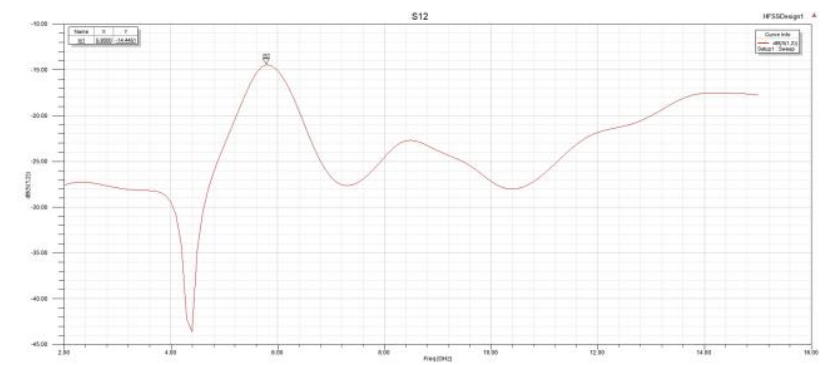

Fig. 7 Isolation $\mathrm{S}_{12}$.

In order to increase the isolation, a parasitic element was implemented between the radiator elements, this is shown in figure 8, a parametric study was carried out, obtaining a parasitic element size $25.27 \times 0.5$ $\mathrm{mm}^{2}$.

Table 1 summarizes the values obtained for the bandwidth, the scattering parameters $S_{11}$ and $S_{12}$ averaged over the entire bandwidth and in the same way, the frequency range of the bandwidth (11.61 $\mathrm{GHz}$ ).

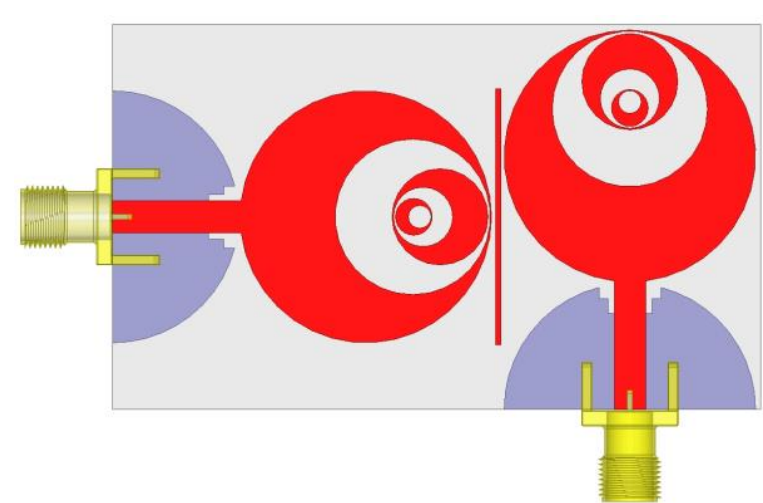

Fig. 8 MIMO antenna with parasitic element.

\begin{tabular}{|c|c|c|c|}
\hline $\begin{array}{c}\text { Low-High cutoff Frequency } \\
\text { (GHz) }\end{array}$ & $\begin{array}{c}\text { Size } \\
\left(\mathbf{m m}^{2}\right)\end{array}$ & $\begin{array}{c}\text { S11 (avg) } \\
\text { (dB) }\end{array}$ & $\begin{array}{c}\text { S12 (avg) } \\
\text { (dB) }\end{array}$ \\
\hline $2.9-14.51$ & $38 \times 64$ & -14.61 & -26.09 \\
\hline
\end{tabular}

Table 1. Performance parameter of the MIMO antenna.

The return losses $S_{11}$ are shown in figure 9, can be seen that a mismatching peak is still present, the peak improves to a maximum peak of $\mathrm{S}_{11 \max }=-9.84 \mathrm{~dB}$ (VSWR <2). The frequency range of the mismatching is $4.8-5.1 \mathrm{GHz}$.

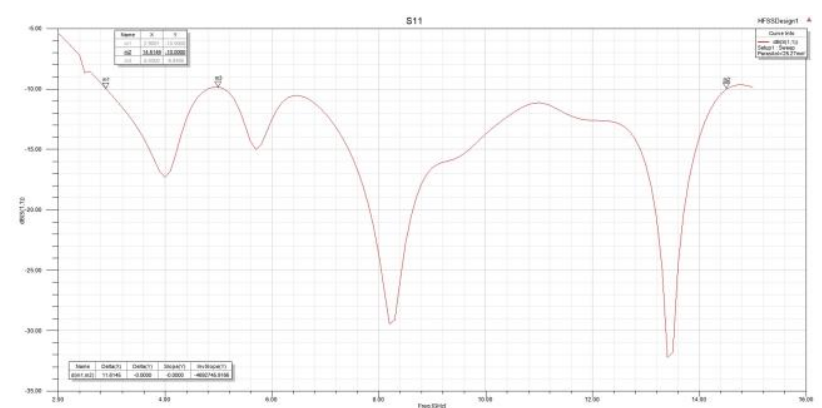

Fig. 9 Return losses $\mathrm{S}_{11}$ with parasitic element.

The figure 10 shows the isolation obtained, a maximum peak of $\mathrm{S}_{12 \max }=18.76 \mathrm{~dB}$ at a frequency of $5.9 \mathrm{GHz}$ and an average $\mathrm{S}_{12 \text { avg }}=-26.09$ (table 1) over the entire bandwidth, complying with the minimum isolation requirement.

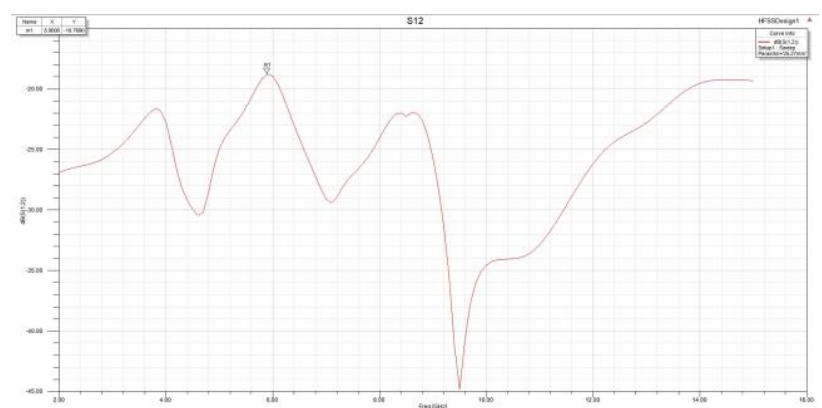

Fig. 10 Isolation $S_{12}$ with parasitic element.

Figure 11 shows the distribution of currents in the antenna with and without a parasitic element, the 
surface currents distribution was reduced in the MIMO antenna when a parasitic element is used.

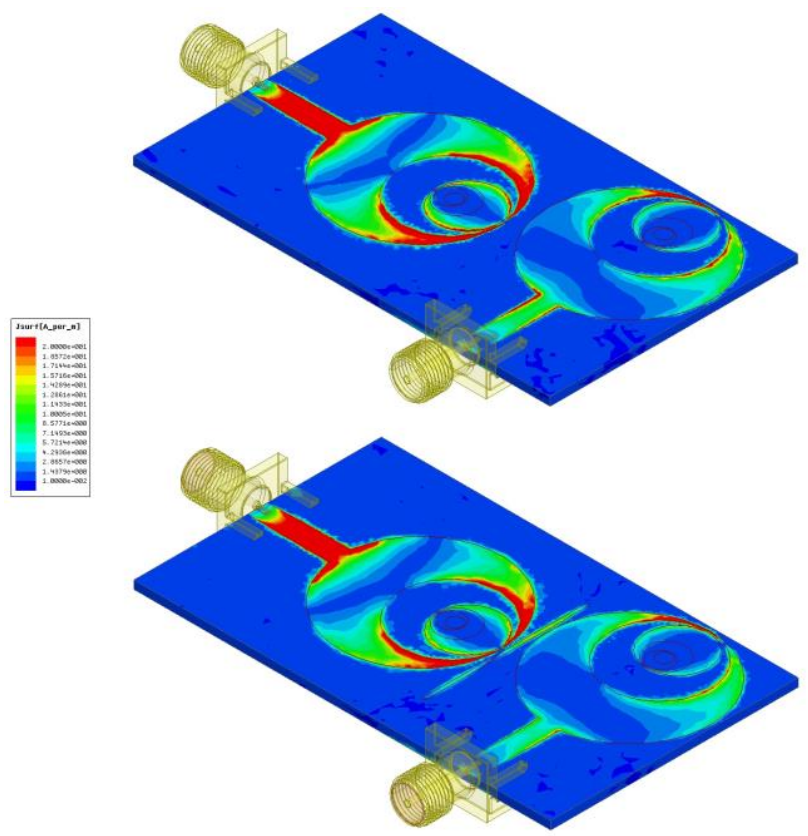

Fig. 11 Surface current distribution in MIMO antenna without and with parasitic element.

The Envelop Correlation Coefficient (ECC) is a quantity that shows the degree of correlation between the fields radiated by two ports, it can be calculated using the scattering parameters $\mathrm{S}$ (equation 1) or the radiation pattern (equation 2) [15].

$$
\begin{gathered}
E C C=\frac{\left|S_{11}{ }^{*} S_{12}+S_{21}{ }^{*} S_{22}\right|^{2}}{\left(1-\left|S_{11}\right|^{2}-\left|S_{21}\right|^{2}\right)\left(1-\left|S_{22}\right|^{2}-\left|S_{12}\right|^{2}\right)} \\
E C C=\frac{\left|\iint_{4 \pi}\left[\overrightarrow{F_{1}}(\theta, \varphi) \cdot \overrightarrow{F_{2}}(\theta, \varphi)\right] d \Omega\right|^{2}}{\iint_{4 \pi}\left|\overrightarrow{F_{1}}(\theta, \varphi)\right|^{2} d \Omega \iint_{4 \pi}\left|\overrightarrow{F_{2}}(\theta, \varphi)\right|^{2} d \Omega}
\end{gathered}
$$

The ECC was obtained using the Ansys HFSS (High Frequency Structure Simulator) software, getting $\mathrm{ECC}<0.0076$ as can be seen in figure 12 .

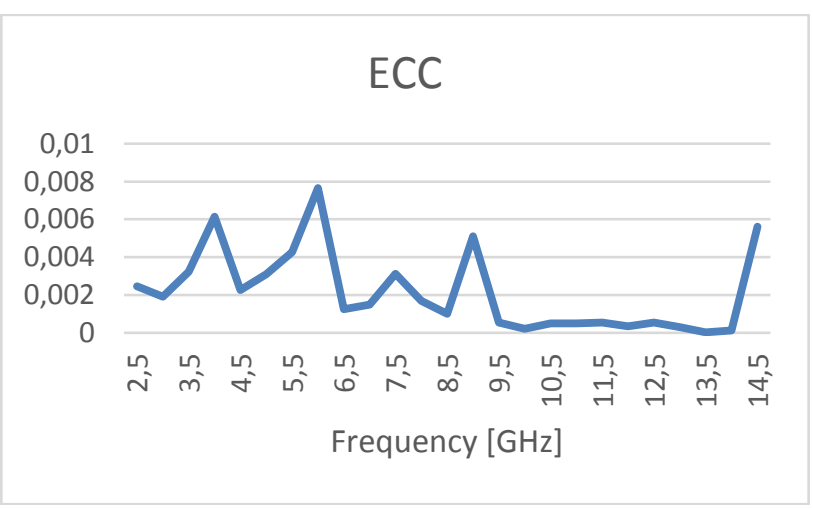

Fig. 12 ECC for ports 1 and 2.
Diversity Gain (DG) shows the improvement in the performance of the System or the reliability with the minimum use of power to transmit [16]. The Diversity gain is presented in table 2 and shows high gain due to low ECC levels.

\begin{tabular}{|c|c|}
\hline $\begin{array}{c}\text { Frequency } \\
(\mathbf{G H z})\end{array}$ & $\begin{array}{c}\text { DG } \\
(\mathbf{d B})\end{array}$ \\
\hline 2.5 & 19.999974 \\
\hline 3 & 19.999984 \\
\hline 3.5 & 19.999954 \\
\hline 4 & 19.999836 \\
\hline 4.5 & 19.999978 \\
\hline 5 & 19.999959 \\
\hline 5.5 & 19.999921 \\
\hline 6 & 19.999746 \\
\hline 6.5 & 19.999993 \\
\hline 7 & 19.99999 \\
\hline 7.5 & 19.999958 \\
\hline 8 & 19.999988 \\
\hline 8.5 & 19.999996 \\
\hline
\end{tabular}

\begin{tabular}{|c|c|}
\hline $\begin{array}{c}\text { Frequency } \\
(\mathbf{G H z})\end{array}$ & $\begin{array}{c}\text { DG } \\
(\mathbf{d B})\end{array}$ \\
\hline 9 & 19.999887 \\
\hline 9.5 & 19.999999 \\
\hline 10 & 20 \\
\hline 10.5 & 19.999999 \\
\hline 11 & 19.999999 \\
\hline 11.5 & 19.999999 \\
\hline 12 & 19.999999 \\
\hline 12.5 & 19.999999 \\
\hline 13 & 20 \\
\hline 13.5 & 20 \\
\hline 14 & 20 \\
\hline 14.5 & 19.999863 \\
\hline \multicolumn{2}{|c}{} \\
\hline
\end{tabular}

Table 2. Diversity Gain

The 3D radiation pattern in Figure 13 shows a quasiomnidirectional behavior which is convenient for mobile applications.
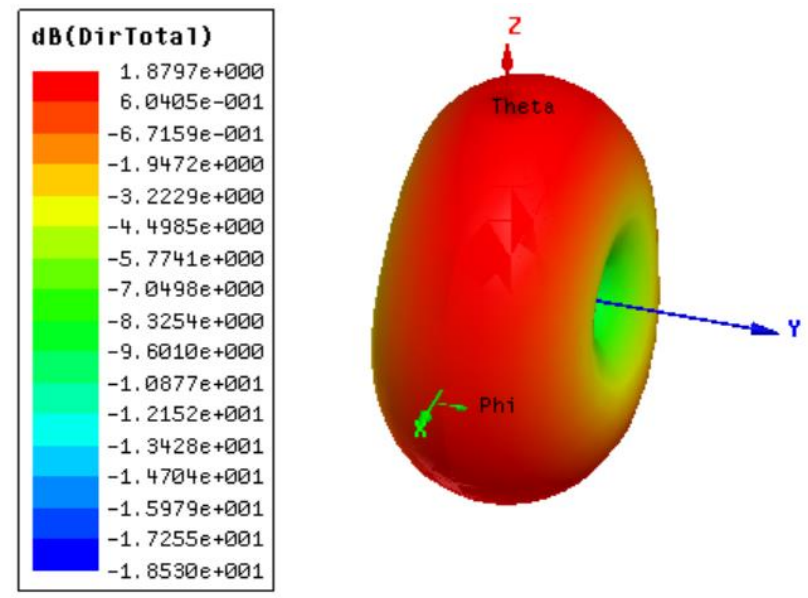

Fig. 13. 3D Radiation pattern of MIMO antenna.

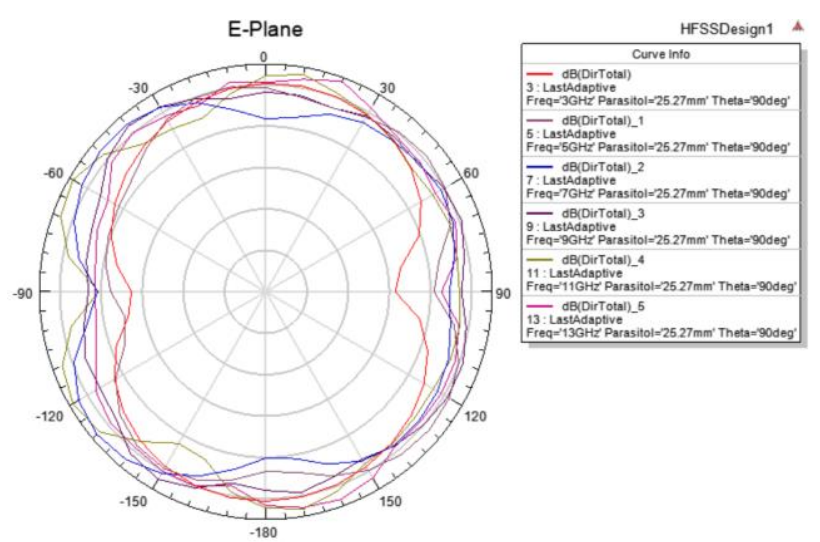

Fig. 14 Radiation Pattern (E-Plane) of UWB MIMO antenna at 3, 5, 7, 9, 11 and $13 \mathrm{GHz}$. 
Figure 14 shows the behavior over the entire bandwidth presented on the E plane, the stability of the radiation pattern varies slightly, giving an adequate behavior over the entire UWB bandwidth.

Finally, the Total Active Reflection Coefficient (TARC) was obtained. The TARC shows the port matching and the variation of the incoming signals due random values of their phases. The TARC for two antennas is defined like in equation 3 , according to the scattering parameters [17].

$$
T A R C=\frac{\sqrt{\left|S_{11}+S_{12} e^{j \theta}\right|^{2}+\left|S_{21}+S_{22} e^{j \theta}\right|^{2}}}{\sqrt{2}}
$$

The variation of the TARC was obtained using random values of the phases of the signals as shown in figure 15.

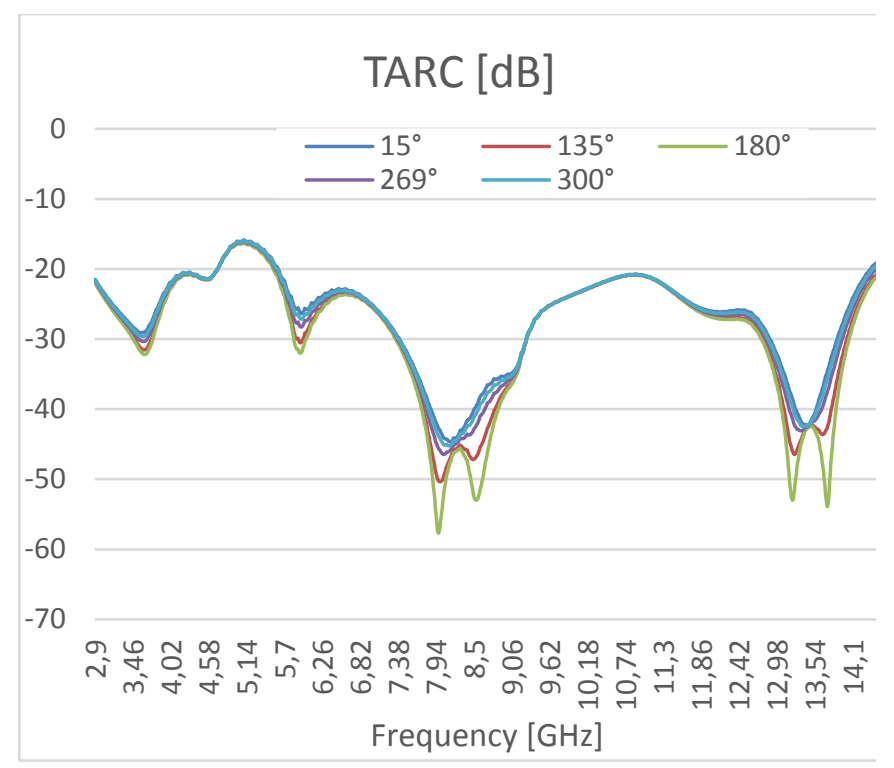

Fig. 15. TARC with five different phases.

In figure 15 the curves were made for five different phase values, showing a high stability of the TARC over the entire bandwidth achieved (2.9-14.51 GHz).

\section{Conclusion}

The MIMO antenna achieves a VSWR $<2$ within the frequencies range from 2.9 to $14.5 \mathrm{GHz}$.

With a simple implementation of a parasitic element, the size $(38 \times 64 \mathrm{~mm} 2)$ of the two-element MIMO antenna was reduced to the maximum, complying with the necessary isolation required in $4 \mathrm{G}$ systems.
The antenna presents a high isolation over the entire frequency range, in addition to a high stability of the TARC at random values of the input signal phases. The radiation pattern of the MIMO antenna is suitable for mobile applications and does not show significant changes over the entire bandwidth.

\section{Acknowledgment}

This work was supported by the research project "Diseño, Desarrollo y evaluación de antenas de banda ultra ancha (UWB) para aplicaciones en la banda de 3.1 GHz a 10.6 GHz." (EL002-20). From Metropolitan Autonomous University Azcapotzalco.

\section{References:}

[1]. A. F. Molisch, "Ultra-Wideband Communications: An Overview," URSI Radio Science Bulletin, Vol. 2009, No. 329, pp. 31-42, june, 2009.

[2]. R. S. Kshetrimayun, "An Introduction to UWB Communication Systems," IEEE Potentials, Vol. 28, No. 2, pp. 9-13, April, 2009.

[3]. M. S. Sharawi, "Printed Multi-Band MIMO Antenna Systems and Their Performance Metrics," IEEE Antennas and Propagation Magazine, Vol. 55, No. 5, pp. 218-232, October 2013.

[4]. Raj Kumar, Dhananjay Magar, K. Kailas Sawant, "On the design of inscribed triangle circular fractal antenna for UWB applications," International Journal of Electronics and Communications (AEÜ), vol. 6, No. 1, january, pp. 68-75, 2012.

[5]. S. S. Bhatia and J. S. Sivia, "A Novel Design of Wearable Fractal Antenna for Wideband Applications," International Conference on Advances in Human Machine Interaction (HMI - 2016), March, 2016.

[6]. S. Bukkawar, V. Ahmed, "Omnidirectional and directional fractal UWB monopole antenna," 2017 International Conference on Nascent Technologies in Engineering (ICNTE), pp. 1-4, 2017.

[7]. R. Kubacki, M. Czyżewski and D. Laskowski, "Microstrip antennas based on fractal geometries for UWB application", 2018 22nd International Microwave and Radar Conference (MIKON), pp. 352-356, 2018.

[8]. B. Hu, F. Tang, P. Chen and X. Yu, "Fractal UWB patch antenna with omnidirectional 
pattern," 2017 Sixth Asia-Pacific Conference on Antennas and Propagation (APCAP), October 2017.

[9]. I. Ganesan and P. Iyampalam, "A Review of Ultra-Wideband Fractal Antennas," 2018 Second International Conference on Inventive Communication and Computational Technologies (ICICCT), April, 2018.

[10].J. B. Benavides, R. A. Lituma, P. A. Chasi, L. F. Guerrero, "A Novel Modified Hexagonal Shaped Fractal Antenna with Multi Band Notch Characteristics for UWB Applications," 2018 IEEE-APS Topical Conference on Antennas and Propagation in Wireless Communications (APWC), september, 2018.

[11].S. Upadhyay and L. Jain, "Fractal Antenna for UWB Applications: A Review," International Journal of Computer Applications, Vol. 145, No. 9, July, 2016.

[12].A. Ch. J. Malathi and D. Thiripurasundari, "Review on Isolation Techniques in MIMO Antenna Systems," Indian Journal of Science and Technology, Vol 9, No. 35, pp. 1-10, September, 2016].

[13].J. A. Tirado, D. Martinez, H. Jardon, R. Flores and E. A. Andrade, "Inscribed Fibonacci Circle Fractal in a Circular Radiator for UltraWideband Antenna Operation and Size Reduction," International Journal of Antennas and Propagation, Vol. 2019, pp. 1-8, February, 2019.

[14].J. A. Tirado, D. Martinez, H. Jardon, R. Flores and E. A. Andrade, "Inscribed Fibonacci Circle Fractal in a Circular Radiator for UltraWideband Antenna Operation and Size Reduction," International Journal of Antennas and Propagation, Vol. 2019, pp. 1-8, February, 2019.

[15].Votis C., Tatsis G. and Kostarakis P., "Envelope Correlation Parameter Measurements in a MIMO Antenna Array Configuration," International Journal of Communications, Network and System Sciences, Vol. 3, No. 4, pp. 350-354, April, 2010.

[16].Poudel K. N. and Gangaju S., "Spectral Efficiency, Diversity Gain and Multiplexing Capacity Analysis for Massive MIMO, 5G Communications System," 2017 International Conference on Networking and Network Applications, pp. 133-137, Nepal, october, 2017.

[17].Erik Fritz-Andrade, Hildeberto Jardon-Aguilar and Jose A. Tirado-Mendez, "The correct application of total active reflection coefficient to evaluate MIMO antenna systems and its generalization to N ports," International Journal of RF and Microwave Computer-Aided Engineering, 2020.

\section{Creative Commons Attribution License 4.0 (Attribution 4.0 International, CC BY 4.0)}

This article is published under the terms of the Creative Commons Attribution License 4.0

https://creativecommons.org/licenses/by/4.0/deed.en_US 